Article

\title{
Análise de Ocorrências de Incêndios Florestais na Área do Parque Estadual do Cocó, Região Metropolitana de Fortaleza, CE
}

\author{
João Eufrásio Ferreira Filho $^{1}$ (D), Alexandre Costa Araújo $^{2}$ \\ ${ }^{1}$ Corpo de Bombeiros Militar do Estado do Ceará, Secretaria de Segurança Pública e Defesa \\ Social, Fortaleza, CE, Brasil. \\ ${ }^{2}$ Mestrado Profissional em Climatologia e Aplicações nos Países da CPLP e África, Universidade \\ Estadual do Ceará, Fortaleza, CE, Brasil.
}

Recebido em: 3 de Março de 2021 - Aceito em: 26 de Abril de 2021

\begin{abstract}
Resumo
Os incêndios florestais apresentam riscos ao meio ambiente, assim como consequências econômicas consideráveis, destruindo hábitats e grande parte de matéria orgânica, queima de madeira e altos custos para o seu controle e combate. Os órgãos competentes, para estabelecer políticas de controle e prevenção, necessitam conhecer o perfil dos incêndios. Dados estatísticos de ocorrências dessa natureza tornam-se os principais subsídios para se entender e traçar o seu perfil. De posse desses dados, torna-se possível planejar ações para controle de modo mais eficiente, evitando e minimizando gastos, tempo e riscos em seu combate. Os objetivos deste estudo visaram quantificar o número de incêndios e determinar os meses do ano de maiores ocorrências de incêndios florestais no Parque Estadual do Cocó. Para isso, foi utilizado um período temporal de 20 anos (1999-2018), com dados de sinistros de incêndios. Os resultados apontaram como "estação normal de incêndios florestais" o período do segundo semestre. Em relação aos meses, destacaram-se o período de agosto a dezembro, tendo o mês de novembro o maior número de registros e com maior risco de sinistros, seguido por dezembro, outubro, setembro e agosto, que também corresponde ao período de aumento das temperaturas mínimas e máximas, com a queda no número de precipitações.
\end{abstract}

Palavras-chave: incêndios florestais, meses do ano e Parque Estadual do Cocó.

\section{Analysis of Forest Fire Occurrences in the Cocó State Park Area, Metropolitan Region of Fortaleza, CE}

\begin{abstract}
Forest fires present risks to the environment, as well as considerable economic consequences, destroying habitats and a large part of organic matter, burning wood and high costs for their control and combat. The competent bodies, in order to establish control and prevention policies, need to know the fire profile. Statistical data of occurrences of this nature become the main subsidies to understand and outline your profile. With this data, it becomes possible to plan actions for control in a more efficient way, avoiding and minimizing expenses, time and risks in its combat. The objectives of this study were to quantify the number of fires and determine the months of the year with the highest occurrences of forest fires in the Parque Estadual do Cocó. For this, a 20-year time period (1999-2018) was used, with data on fire claims. The results indicated that the second semester was the "normal forest fire season". Regarding the months, the period from August to December stood out, with the month of November having the highest number of records and with the highest risk of claims, followed by December, October, September and August, which also corresponds to the period of increase in minimum and maximum temperatures, with the fall in the number of precipitations.
\end{abstract}

Keywords: forest fires, months of the year and Cocó, State Park.

Autor de correspondência: João Eufrásio Ferreira Filho, joaojeff@gmail.com. 


\section{Introdução}

O atual cenário climático é bastante preocupante devido ao acelerado aquecimento global observado nos últimos anos. Muitos alertas têm sidos emitidos e observados pelos cientistas que demonstram a preocupação e a importância que a temática representa para o meio ambiente. Os inúmeros congressos, reuniões e eventos científicos na área como os do Painel Intergovernamental sobre Mudanças Climáticas (IPCC) apontam para intensas mudanças climáticas globais, com possibilidade de agravamento dos danos ao meio ambiente como o crescente número de incêndios florestais, como os vistos recentemente até mesmo nas Regiões da Sibéria, Alasca e Groenlândia (CLIMAINFO, 2019).

O mais recente relatório científico do IPCC (2018) destacou a importância de limitar o aquecimento global a $1,5{ }^{\circ} \mathrm{C}$ em relação ao Período pré-industrial, ressaltando também a necessidade crítica de uma ação climática urgente. Os cientistas apontam o relatório como o texto científico mais importante sobre as mudanças climáticas, principalmente, para que sejam intensificadas a implementação de ações concretas que venham a diminuir a emissão de gases do efeito estufa (WWF, 2018).

No Brasil, identificou-se o desmatamento como grande responsável pelas emissões dos gases do efeito estufa. Geralmente, acompanhado das queimadas fora de controle, o desmatamento vem destruindo várias áreas importantes como na região Amazônica, no Cerrado e nas áreas de Mata Atlântica (WWF, 2018). Ao longo dos anos, a população vem assistindo à propagação de inúmeros incêndios florestais não somente no Brasil, mas em todo o mundo (BBCNEWS/BRASIL, 2020). Desastres naturais dessa natureza vêm chamando atenção pela dimensão e por terem se tornado mais frequentes. A Europa, na região de Portugal, e os Estados Unidos vêm sofrendo todos os anos com ocorrências como essa, que geram inúmeros transtornos, entre os quais, doenças respiratórias, degradação do meio ambiente, emissões de gases na atmosfera, destruição de patrimônios e, até perda de vidas.

$\mathrm{O}$ aumento do número de queimadas e incêndios florestais, no mundo, teve inicio a partir da década de 1960, com a destruição e o desmatamento de grandes áreas de florestas (Ramos, 2004). Os incêndios florestais, além de trazer mais destruição para a vegetação, ocasionaram também os inconvenientes decorrentes da poluição atmosférica, como mudanças climáticas locais. Além disso, o maior número de incêndios florestais contribuiu, por sua vez, para aumentar a vulnerabilidade das unidades de conservação espalhadas pelo mundo (Saraiva, 2011).

\subsection{Incêndios florestais no Brasil}

Particularmente, no Brasil, as condições adversas ao meio ambiente vêm contribuindo para o aumento do número de focos de incêndios florestais. A estiagem prolon- gada, a vegetação seca, a baixa umidade relativa do ar e os baixos índices pluviométricos são fatores importantes que precisam ser levados em consideração para analisar esse aumento. Na década de 2000, o Centro Nacional de Prevenção e Combate aos Incêndios Florestais - PREVFOGO/IBAMA - (2009) considerou o ano de 2007 como o 'ano do fogo', justamente, por ter apresentado várias dessas condições desfavoráveis na natureza, que culminaram com um grande número de incêndios florestais.

No ano anterior, em 2006, o Centro de Operações dos Bombeiros, já destacava um aumento de $25 \%$, no número de ocorrências de fogo em vegetação, comparado ao ano de 2005 , passando assim de 5.436 para 6.822 de sinistros (IEF/RJ, 2007, citado por Rodrigues, 2008). Para comprovar ainda mais esse aumento, o IEF, apontou que entre janeiro e outubro de 2007, já haviam sido detectados mais de 8 mil incêndios florestais, tendo assim atingido um recorde negativo histórico, superando anos anteriores como o de 2001, que chegou a registrar 7.732 ocorrências de janeiro a dezembro.

Outro fator importante para o aumento de incêndios, no Brasil, é o avanço de novas frentes nas áreas de pecuária, de extração de madeira e a abertura de áreas para monoculturas de grãos (Castro, 2005). Em regiões como a Amazônia, as intensas atividades econômicas para produção agropecuária têm relação direta com o alto número de incêndios florestais, confirmando-se pela grande quantidade de ocorrências. Anteriormente, alguns estudos já apontavam que $16 \%$ das áreas atingidas pelo fogo na fronteira agrícola da Amazônia eram decorrentes do fogo colocado de maneira intencional e negligente para derrubadas de florestas (Nepstad et al., 1999). Dados atuais confirmam que, na Amazônia brasileira, as taxas de alerta de desmatamento estão ligadas à incidência de fogo, sendo uma das principais ferramentas utilizadas para desmatar (GREENPEACE/BRASIL, 2019, citado por Ferreira Filho, 2019).

As áreas de desmatamento vêm crescendo em alguns estados, não somente em áreas de floresta amazônica, mas também no cerrado. A atividade agropecuária figura como a provável causa das ocorrências de incêndio, isto porque se necessita de grandes áreas para pastagem e produção de grãos. Sendo assim, o desmatamento é outro fator que pode estar contribuindo para o alto índice de registro de incêndios no Brasil (INPE, 2010, citado por Ferreira Filho, 2019).

Ressalta-se que o número de ocorrências de fogo nas florestas brasileiras é mais expressivo entre os meses de julho e novembro porque as condições climáticas neste período favorecem o surgimento e propagação de focos de incêndio na vegetação local (PREVFOGO/IBAMA, 2007, citado por Ferreira Filho, 2019). Batista (2000) e o INPE (2009, citado por Ferreira Filho, 2019) acrescentam que a concentração dessas ocorrências, nos últimos meses do ano, é resultado das variações climáticas como escassez de 
chuvas em várias regiões brasileiras, bem como temperaturas máximas, que vêm excedendo médias históricas.

Portanto, as condições climáticas adversas de cada ano é que determinarão o número de ocorrências de incêndios florestais. Mesmo assim, apesar de estar interligado às condições naturais desfavoráveis, o número de ocorrências desse tipo dependerá, principalmente, da ação da humanidade. O IBAMA (2009) aponta que os maiores causadores de incêndios florestais ainda são o vandalismo e a renovação de pastagens. Sendo a abertura de novas frentes agrícolas, como a de soja, e a de pastagens, os maiores vilões de sinistros dessa natureza no Brasil.

$\mathrm{O}$ ano de 2020 ficou marcado por grandes números de ocorrências de incêndios florestais, principalmente na Amazônia brasileira e Pantanal brasileiro, o que gerou grandes críticas e fortes repercussões internacionais. Além desses biomas, outras áreas importantes vêm sofrendo com o aumento do número de incêndios florestais, como as diversas áreas verdes espelhadas pelo país, entre Parques e Reservas florestais.

Especificamente, no Estado do Ceará, a Região Metropolitana de Fortaleza apresenta uma importante área verde que corta vários bairros da cidade, o Parque Estadual do Cocó. A localização geográfica do parque inserido dentro de um grande centro urbano contribui para uma relação muitas vezes conflituosa com o homem, na qual se apresenta com grandes problemas de muitas áreas desmatadas e com um grande número de ocorrências de incêndio florestal atendidas dentro e nas áreas limites do parque com o meio urbano.

Atualmente, a política ambiental tem se preocupado na preservação das áreas verdes remanescentes de florestas próximas e dentro das grandes cidades. Regiões com essas características são importantes como reguladoras de microclimas, agem para reduzir impactos ambientais de eventos extremos, além de serem importantes reservas de carbono. Nesse sentido, a regulamentação do Parque Estadual do Cocó como Unidade de Conservação de Proteção Integral, no ano de 2017, foi um importante passo para um maior controle e preservação da área. O Estado, atuando na gestão ambiental do parque, pode assim fiscalizar e monitorar com mais eficiência a vegetação do Parque. A identificação dos fatores de risco e, principalmente, das áreas mais vulneráveis é essencial tanto na questão preventiva, como também para rápidas respostas dos órgãos competentes.

Dessa forma, o presente trabalho tem como objetivos quantificar as ocorrências de incêndios florestais dentro do Parque Estadual do Cocó, entre os anos de 1999 e 2018, e identificar os meses do ano de maiores ocorrências de incêndios florestais, bem como oferecer este estudo como instrumento para que o Estado e a população possam realizar ações de caráter preventivo, que venham a minimizar que ameaças de incêndios florestais dentro ou próximas ao parque ocorram em menor número e frequência.

\section{Materiais e Métodos}

Para a realização deste estudo foi utilizada uma série temporal de 20 anos (1999 - 2018), com dados de sinistros de incêndios florestais dentro do Parque Estadual do Cocó. As informações obtidas serviram de base documental para construção da pesquisa. Sendo assim, os documentos disponibilizados que serviram como base de pesquisa consiste em dados de ocorrências a incêndios florestais que foram registrados pela Secretária do Meio Ambiente do Estado do Ceará (SEMA/CE) e pela Coordenadoria Integrada de Operações de Segurança do Estado do Ceará (CIOPS/CE), especificamente, na área do Parque Estadual do Cocó. As 182 ocorrências de incêndios florestais, na área do Parque, foram registradas e atendidas pelo Corpo de Bombeiros Militar do Estado do Ceará (CBMCE).

Destaca-se que a pesquisa levou em consideração a área que, antes do ano 2017, não fazia parte da nova delimitação e regulamentação do Parque como Unidade de Conservação de Proteção Integral. Os dados coletados na pesquisa documental foram quantificados e utilizadas técnicas de estatística básica, tanto na coleta dos dados quanto no tratamento deles. Tendo a soma das ocorrências mensais possibilitado a construção do gráfico meses do ano x número de ocorrências entre os anos de 1999 e 2018.

A estação "normal" dos incêndios florestais foi determinada analisando o histórico dos últimos 30 anos de precipitações e temperaturas máximas e mínimas na Região Metropolitana de Fortaleza. Sendo esses elementos climáticos, os que melhor se relacionaram com a quantidade mensal de ocorrências. Assim, determinados os elementos climáticos mais correlacionados com as ocorrências, sua distribuição mensal foi analisada em conjunto com a distribuição mensal dos incêndios florestais do parque, estabelecendo-se a "estação normal do fogo" na área de estudo.

\section{Resultados e Discussões}

A história propicia o entendimento de fatos que estão ocorrendo no presente e pode indicar os possíveis rumos para o futuro. Nesse sentido a análise estatística das ocorrências de incêndios florestais no Parque Estadual do Cocó visa buscar informações que contenham essa interrelação tão próxima entre o homem e a natureza.

Conhecer o histórico referente aos incêndios florestais ocorridos na área de estudo é fundamental para ações estratégicas de planejamento e prevenção. A falta de conhecimento e informações pode levar a situações extremas: elevados gastos preventivos por falta de conhecimento do potencial de danos ou redução de investimentos, colocando em risco toda a sobrevivência do ambiente biológico de uma floresta (Tebaldi et al., 2012).

Basicamente, a elaboração de programas de prevenção utiliza como dados frequentes as causas dos incên- 
dios, a época em que ocorreu, a localização aproximada e, quando possível, identificar a extensão da área queimada. Saber onde os incêndios ocorrem é importante para definir as regiões de maior risco e assim realizar trabalho preventivo nestas. Identificar como ocorre a distribuição dos incêndios através dos meses do ano, também se torna importante para planejamento preventivo, tendo em vista que existem épocas de maior risco de incêndios florestais. Conhecer a extensão das áreas queimadas é importante para analisar a eficiência no combate, principalmente, porque quanto melhor à eficiência das equipes de planejamento, combate e controle, menor é a extensão da área queimada (Batista e Soares, 1997).

Algumas dessas informações podem ser coletadas no registro das ocorrências. Foram utilizadas apenas aquelas ocorrências identificadas dentro da área delimitada em 2017, como pertencente ao Parque Estadual do Cocó. Portanto, áreas próximas, vizinhas ou as chamadas zonas de amortecimento que fazem limite com o parque não foram contabilizadas. A divisão da análise ano a ano auxiliará na identificação, entendimento e discussão sobre essas informações. Os dados obtidos entre os anos de 1999 e 2018 auxiliarão na construção do mapeamento das áreas de risco, tão importante para planejamento de crises e, principalmente, realização de trabalhos preventivos.

No estudo consta a análise de 17 anos de incêndios florestais no Parque Estadual do Cocó. Infelizmente, 3 anos (2000, 2002 e 2013) não foi possível realizar a aná- lise dos dados devido à falta de acesso a essas informações, o que não representa comprometimento da pesquisa, apesar de sua importância. Contudo os dados obtidos apresentaram algumas peculiaridades, como um comportamento padrão que parece se repetir ano a ano.

Resumidamente, nos 17 anos, foram analisadas um total de 182 ocorrências de incêndios florestais na área do Parque Estadual do Cocó. Desse total, 04 não foram utilizadas para construção dos gráficos devido à falta de informações precisas sobre os meses em que ocorreram. Sendo assim, das 178 ocorrências utilizadas, $22(12,36 \%)$ ocorreram no primeiro semestre e $156(87,64 \%)$ ocorreram no segundo semestre, o que demonstra ocorrer um número bastante elevado de sinistros no segundo semestre quando comparados com o primeiro.

Numericamente, os sinistros ficaram distribuídos da seguinte maneira: $14(7,87 \%)$ no mês de janeiro, 5 $(2,81 \%)$ no mês de fevereiro, $1(0,56 \%)$ no mês de março, $1(0,56 \%)$ no mês de abril, $1(0,56 \%)$ no mês de junho, 8 $(4,5 \%)$ no mês de julho, $21(11,8 \%)$ no mês de agosto, 26 $(14,61 \%)$ no mês de setembro, $29(16,29 \%)$ no mês de outubro, $41(23,03 \%)$ no mês de novembro e $31(17,42 \%)$ no mês de dezembro. Assim, destaca-se o mês de novembro com maior número de registros e com maior risco de sinistros, seguido por dezembro, outubro, setembro e agosto. Acrescenta-se ainda o ano 2005 que apresentou o maior número de ocorrências registradas (Total de 34 sinistros), apresentando também o maior número de regis-

\section{Registros de incêndios florestais no Parque Estadual do Cocó por meses do ano entre 1999 e 2018}

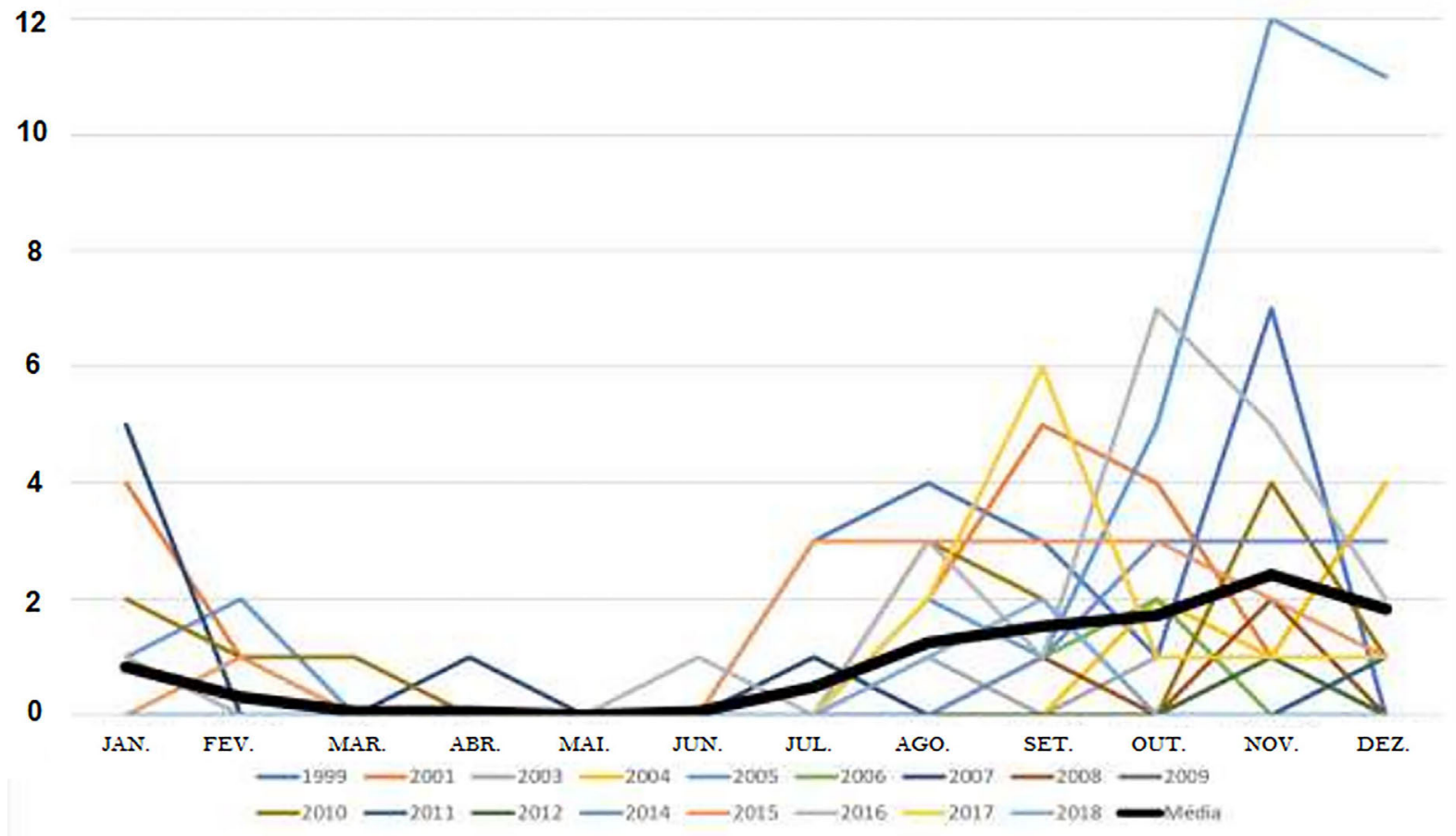

Figura 1 - Registros de incêndios florestais no Parque Estadual do Cocó por mês do ano, entre 1999 e 2018. 
tros por mês, com 12 registros em novembro e 11 em dezembro.

Apesar de alguns anos apresentarem um maior número de registro de sinistros comparado a outros anos, o número médio de ocorrências durante esses 17 anos analisados demonstra os meses com maior risco de incêndios florestais ocorrerem. O período de agosto a dezembro apresenta assim uma média entre 1 a 2 ocorrências por ano, enquanto os demais meses com média inferior a 1 (Fig. 1).

Vale destacar que mesmo as áreas próximas, vizinhas ou zonas de amortecimento não sendo consideradas áreas do Parque Estadual do Cocó, as mesmas apresentaram um alto número de ocorrências em alguns locais como, por exemplo, na ARIE (Áreas de Relevante Interesse Ecológico) das Dunas do Cocó. Incêndios nessas áreas não foram contabilizados, porque além de não serem locais considerados oficialmente área do parque, em várias situações muitas vezes era impossível identificar onde terminavam as zonas de amortecimento e iniciava a área do Parque Estadual do Cocó. Essa confusão acontece devido a essa divisão de áreas ser demarcada apenas por uma linha imaginária, o que não deveria ocorrer, pois as áreas próximas e o Parque Estadual do Cocó apresentam as mesmas características de vegetação, que para propagação dos incêndios florestais não fará a menor diferença, pois toda a área será queimada. Portanto, esses registros também deveriam ser levados em consideração.

Sendo assim, nos 17 anos, foram identificadas 42 ocorrências de incêndios florestais na Zona de Amortecimento, próxima a área do Parque Estadual do Cocó. Especificamente, $2(4,76 \%)$ ocorreram no primeiro semestre e $40(95,24 \%)$ ocorreram no segundo semestre, o que demonstra ocorrer um número bastante elevado de sinistros no segundo semestre quando comparados com o primeiro. Numericamente, os sinistros ficaram distribuídos da seguinte maneira: 2 (4,76\%) no mês de janeiro, 3 (7,14\%) no mês de agosto, $10(23,81 \%)$ no mês de setembro, 9 $(21,43 \%)$ no mês de outubro, 9 (21,43\%) no mês de novembro e $9(21,43 \%)$ no mês de dezembro. Destaca-se o mesmo padrão de distribuição de ocorrências nessas áreas próximas quando comparadas com áreas oficiais dentro do Parque, demonstrando assim uma inter-relação entre as mesmas.

\subsection{Relação entre a climatologia e os incêndios florestais no Parque Estadual do Cocó}

Peculiarmente, no contexto temporal anual, os dados apontaram um comportamento com grande número de registros no segundo semestre, entre os meses de julho e dezembro (Fig. 1). A reunião de todos esses dados anuais torna esse comportamento ainda mais evidente (Fig. 1), o que parece realmente demonstrar existir um comportamento padrão que se repete todos os anos.
Historicamente, no Estado do Ceará, o segundo semestre é reconhecido como o grande período de queimadas em vegetação, que os bombeiros militares do estado, popularmente, denominaram como período de "fogo no mato". Vale salientar que as condições atmosféricas favoráveis do tempo são determinantes para a quantidade de ocorrências dessa natureza. Além disso, padrões de condições do tempo, quando analisados em um determinado período, formam o clima específico do local, que também contribui para explicar o grande número de incêndios florestais em determinadas regiões e épocas do ano.

Sendo assim, o tempo, especificamente, é a condição momentânea da atmosfera, que pode ser analisada através da observação de um período relativamente curto de horas, dias ou, no máximo, semanas. Lembrando que o tempo só pode ser observado conforme sua regularidade e a partir da interpretação dos dados que são gerados após anos de coletas sistematizadas. Já o clima, que representa o conjunto de informações sobre a pressão atmosférica, temperatura e umidade relativa do ar, auxilia na interpretação a respeito das condições atmosféricas de uma determinada localidade, em um período cronológico definido (Cruz et al., 2005).

Apesar do Parque Estadual do Cocó estar inserido em algumas cidades da região metropolitana de Fortaleza, a maior concentração de área do parque encontra-se inserida dentro da capital cearense. Sendo assim, a análise do clima da cidade de Fortaleza já fornece subsídios que auxiliam na interpretação da inter relação entre o clima e o número de incêndios florestais registrados.

A construção de um gráfico sobre o clima de uma determinada localidade se torna possível através do cálculo dos valores das médias climatológicas. Especificamente, o gráfico a seguir foi desenvolvido utilizando-se uma série de dados observados durante 30 anos, e apresenta dados que fornecem uma melhor compreensão da climatologia local da cidade de Fortaleza (Fig. 2).

Dados numéricos como de precipitações e temperaturas mínimas ou máximas são bastante utilizados para entender o comportamento das chuvas e das temperaturas ao longo dos anos. Essas médias climatológicas auxiliam na construção de gráficos e interpretação dos mesmos, sendo assim possível identificar as épocas mais chuvosas ou secas e aquelas mais quentes ou frias de uma determinada região. Esses dados são fundamentais para identificar as épocas do ano com maior risco de incêndios florestais.

A análise dos dados obtidos em conjunto com as condições do tempo ou do clima local demonstra existir uma inter-relação entre o número de ocorrências de incêndios florestais e as condições atmosféricas. Sendo assim, analisando o primeiro semestre dos dois gráficos observase que o gráfico climatológico (Fig. 2) apresenta um histórico de muitas chuvas e com temperaturas máximas de menores valores, enquanto no gráfico de número de ocorrências de incêndios florestais (Fig. 1) ocorre o menor 


\section{Fortaleza - BR}

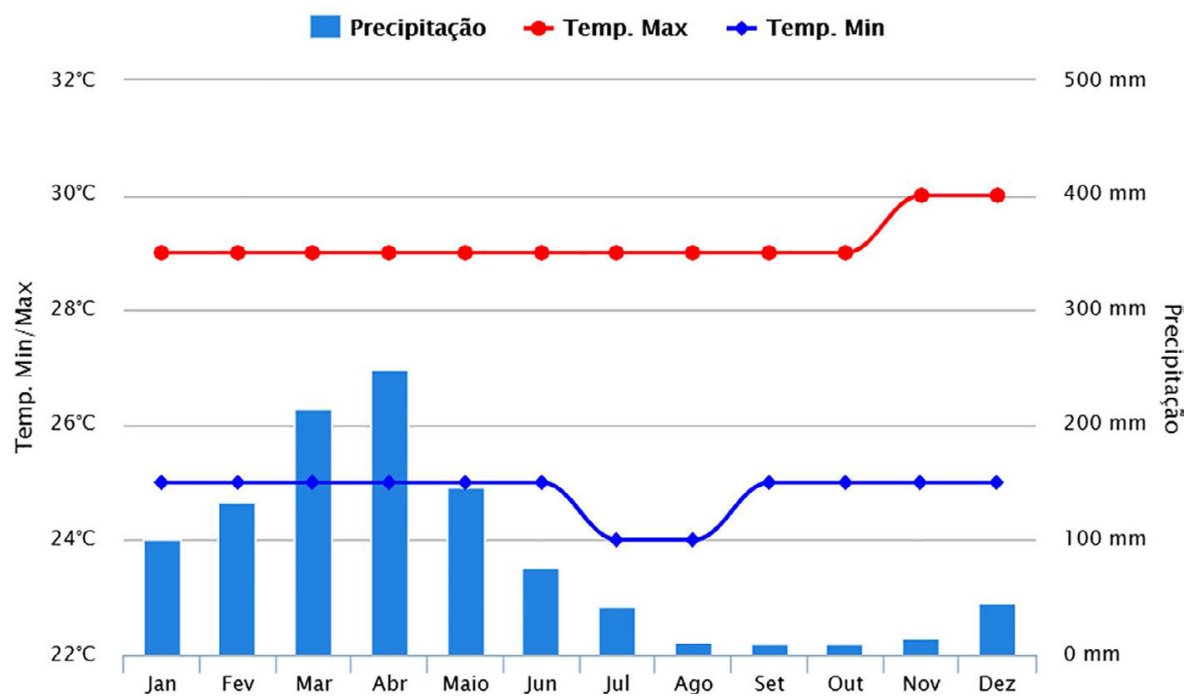

Figura 2 - Registro climatológico da cidade de Fortaleza-CE nos últimos 30 anos. Fonte: Disponível em: https://www.climatempo.com.br/climatologia/ 60/fortaleza-ce. Acesso em: 28 fev. 2021.

número de sinistros. Já na análise do segundo semestre, observa-se que ocorre uma inversão do cenário observado no primeiro semestre, com o gráfico climatológico (Fig. 2) apresentando um histórico de poucas chuvas e com temperaturas máximas de maiores valores, enquanto no gráfico do número de ocorrências de incêndios florestais (Fig. 1) ocorre um aumento do número de sinistros. Ou seja, os dados relativos ao gráfico climatológico comparados com o gráfico de número de ocorrências de incêndios florestais no Parque Estadual do Cocó apresentam uma relação inversamente proporcional entre as precipitações e o número de incêndios, e uma relação diretamente proporcional entre as temperaturas máximas e o número de incêndios florestais.

\section{Considerações Finais}

Após quantificação das ocorrências de incêndios florestais identificou-se uma possível correlação com as precipitações e temperaturas máximas e mínimas na Região Metropolitana de Fortaleza. Sendo esses elementos climáticos, os que melhor se relacionaram com a quantidade mensal de ocorrências.

A análise das ocorrências de incêndios florestais nos últimos vinte anos (1999 a 2018) auxiliou para entender o quão a região é vulnerável a ameaças dessa natureza, podendo-se, assim, identificar os vários riscos envolvidos e minimizá-los. A discussão tentou identificar uma possível relação entre as ocorrências analisadas e os meses do ano em que as mesmas ocorriam, sendo assim, possível inferir alguma inter-relação com os períodos mais quentes e secos.
Assim, determinados os elementos climáticos mais correlacionados com as ocorrências, definiu-se a "estação normal do fogo" na área de estudo do Parque Estadual do Cocó, como sendo os meses de julho, agosto, setembro, outubro, novembro e dezembro, com grande destaque para o período "B-r-o-bró", tendo o mês de novembro apresentado maior risco.

\section{Referências}

BATISTA, A.C. Mapas de risco: uma alternativa para o planejamento de controle de incêndios florestais. Floresta, v. 30, n. $1 / 2$, p. $45-54,2000$.

BATISTA, A.C.; SOARES, R.V. Manual de Prevenção e Combate a Incêndios Florestais. Curitiba: FUPEF, 50 p., 1997.

BBC NEWS BRASIL. Incêndios Florestais Pelo Mundo São os Maiores 'Em Escala e em Emissões de CO2' em 18 anos. Disponível em: https://www.bbc.com/portuguese/ geral-54202546\#: :text $=\% 22$ Um $\% 20$ hectare $\% 20 \mathrm{de} \%$ 20floresta\%20na,2019\%20e\%20julho\%20de\%202020. Acesso em: 16 abr. 2021.

CASTRO, E. Dinâmica socioeconômica e desmatamento na Amazônia. Novos Cadernos NAEA, v. 8, n. 2, p. 5-39, 2005.

CLIMAINFO. Sibéria, Alasca e Groenlândia em Chamas. 2019. Disponível em: https://climainfo.org.br/2019/08/01/ incendios-florestais-siberia-alasca-e-groenlandia-em-cha mas/. Acesso em: 16 abr. 2021.

CRUZ, F.N.; BORBA, G.L.; ABREU, L.R.D. Ciências da Natureza e Realidade: Interdisciplinar. Natal: EDUFRN, 348 p., 2005.

FERREIRA FILHO, J.E. Mapeamento das Áreas de Risco de Incêndio Florestal no Parque Estadual do Cocó: A Importância das Áreas Verdes no Atual Cenário Climá- 
tico. Dissertação de Mestrado em Climatologia e Aplicações nos Países da CPLP e África, Universidade Estadual do Ceará, 145 p., 2019.

INSTITUTO BRASILEIRO DO MEIO AMBIENTE E DOS RECURSOS NATURAIS RENOVÁVEIS. Relatório de Ocorrências de Incêndios em Unidades de Conservação Federais, 2005 a 2008. Brasília: IBAMA, 2009.

NEPSTAD, D.C.; MOREIRA, A.G.; ALENCAR, A.A. A Floresta em Chamas: Origens, Impactos e Prevenção de Fogo na Amazônia. Brasília: Ministério do Meio Ambiente, 172p., 1999.

PAINEL INTERGOVERNAMENTAL SOBRE MUDANÇA CLIMÁTICA. About IPCC. 2018. Disponível em: https:// www.ipcc.ch/. Acesso em: 25 out. 2020.

RAMOS, P.C.M. Manual de Operações de Prevenção e Combate aos Incêndios Florestais: Comportamento do Fogo. Brasília: IBAMA, 2004.

RODRIGUES, A.N.C. Considerações Sobre Prevenção e Combate aos Incêndios Florestais no Estado do Rio de Janeiro. Dissertação de Graduação em Engenharia Flores- tal, Universidade Federal Rural do Rio de Janeiro, Seropédica, 28 p., 2008.

SARAIVA, E.A. Detecção de Incêndios Florestais e Queimadas com Radar Meteorológico. Tese de Doutorado em Engenharia Florestal, Universidade Federal do Paraná, Curitiba, 198 p., 2011.

TEBALDI, A.L.C.; FIEDLER, N.C.; SANT'ANNA, C.M.; MINETTE, L.J. Controle de Incêndios Florestais: Contribuições para o Corredor Central da Mata Atlântica. Cariacica: IEMA, 156 p., 2012.

WORLD WIDE FUND FOR NATURE. Novo Relatório do IPCC Sobre Aquecimento de $1,5^{\circ} \mathrm{C}$ Pede Mais Esforços para Ação Climática. 2018. Disponível em: https://www. wwf.org.br/?67822/Relatrio-do-IPCC-2018-sobre-aqueci mento-global-de-15C-incita-mais-esforos-para-ao-clim tica-global. Acesso em: 25 out. 2020.

License information: This is an open-access article distributed under the terms of the Creative Commons Attribution License (type CC-BY), which permits unrestricted use, distribution and reproduction in any medium, provided the original article is properly cited. 